\title{
Komunikasi Transendental Sembahyang Buddha Mahayana (Studi Semiotika Sembahyang Di Vihara Padumuttara Tangerang)
}

\author{
Tania, Suzy S. Azeharie \\ tania.915150112@stu.untar.ac.id,suzya@fikom.untar.ac.id \\ Fakultas Ilmu Komunikasi Universitas Tarumanagara
}

\begin{abstract}
Prayers performed by Mahayana Buddhists at Padumuttara Temple are a form of communication between humans and God to form a meaning that is understood together. So the main focus of this research is to discuss the meaning of semiotics in the transcendental communication of Mahayana Buddhist prayer at Padumuttara Monastery, Tangerang. This research will be elaborated by Roland Barthes's semiotic analysis. The research approach used is descriptive qualitative research. The data used are the results of nonparticipant observation, interviews with sources, library studies and online data searches. The meaning of Mahayana Buddhist Prayer can be seen from the meanings of gestures in prayer, namely wensin, namaskara and pradaksina. In addition, there is also the meaning of the spoken text, namely nien fo. So that it is found that the meaning of Mahayana Buddhist prayer is respect and contemplation of the teachings or Dhamma of the Buddha encompassing the noble qualities of the Buddha.
\end{abstract}

Keywords: Semiotic Meaning, Transcendental communication, Mahayana Buddhism

\begin{abstract}
Abstrak
Sembahyang yang dilakukan oleh umat Buddha Mahayana di Vihara Padumuttara merupakan bentuk kegiatan komunikasi antara manusia dengan Tuhan sehingga membentuk makna yang dipahami bersama. Jadi fokus utama dalam penelitian ini adalah membahas makna semiotika pada komunikasi transendental sembahyang Buddha Mahayana di Vihara Padumuttara Tangerang. Penelitian ini akan diuraikan dengan analisis semiotika Roland Barthes. Pendekatan penelitian yang digunakan adalah penelitian kualitatif deskriptif. Data yang digunakan merupakan hasil dari observasi nonpartisipan, wawancara dengan narasumber, studi kepustakaan dan penelusuran data secara online. Makna Sembahyang Buddha Mahayana dapat dilihat dari makna gerak tubuh dalam sembahyang yaitu wensin, namaskara dan pradaksina. Selain itu juga terdapat makna dari teks yang diucapkan yaitu nien fo sehingga didapatkan makna sembahyang Buddha Mahayana yaitu penghormatan dan perenungan terhadap ajaran atau Dhamma Sang Buddha mencangkup sifat-sifat luhur Buddha.
\end{abstract}

Kata Kunci: makna semiotika, komunikasi transendental, agama Buddha Mahayana

\section{Pendahuluan}

Dalam jurnal yang berjudul Agama dan Kebudayaan dikatakan agama adalah satu dogma, satu pemikiran yang beku dan satu yang harus diyakini oleh manusia (Marzali, 2016). Selanjutnya dalam buku yang berjudul Materi Kuliah Sejarah Perkembangan Agama Budha disebutkan pada permulaan abad ke VIII Masehi antara 700-750 Masehi datang Buddha Mahayana. Mahayana pertama kali masuk ke Sumatera (Materi Kuliah Sejarah Perkembangan Agama Budha, 2003). Selanjutnya 
dalam buku Agama Buddha Mahayana dikatakan kitab-kitab suci aliran Buddha Mahayana ditulis dalam bahasa Sanskerta dan terjemahannya dalam bahasa Tibet dan China. Sedangkan aliran Buddha Theravada menggunakan bahasa Pali (Suzuki, 1939).

Dalam jurnal yang berjudul Eksistensi Agama Konghucu di Indonesia dikatakan pada era kepeimpinannya, Presiden Soeharto mengeluarkan Intruksi Pemerintahan Republik Indonesia No. 14 tahun 1967 berisi tentang melarang seluruh kegiatan beragama yang bersumber dari China. Sehingga orang-orang China tidak memiliki kebebasan dalam menjalankan ritual keagamaan. Agama yang diakui saat itu hanya ada lima yaitu Buddha, Kristen, Katolik, Islam dan Hindu (Aprilia dan Murtiningsih, 2017). Pada saat ini Yuriani mengatakan Konghucu berada di bawah departemen yang sama dengan Buddha (wawancara dengan Yuriani di Sekolah Tinggi Agama Buddha Negeri Sriwijaya pada tanggal 21 Januari 2019 pukul 13.01WIB). Kemudian pada masa kepemimpinan Abdurrahman Wahid kegiatan beragama yang bersumber dari China mulai dipulihkan dengan menerbitkan Keputusan Presiden Nomor 6 Tahun 2000 tentang Pencabutan Instruksi Presiden Nomor 14 Tahun 1967 (http://wisnu.blog.uns.ac.id/2011/03/10/pengakuan-agamakhonghucu-di-indonesia/ di unduh pada tanggal 20 Januari 2019 pukul 13.06 WIB). Saat ini di Indonesia terdapat sekitar 1,7 juta jiwa pemeluk agama Buddha menurut data Biro Pusat Statistik tahun 2010 (https://www.bps.go.id/ diunduh pada 17 Oktober 2018 pukul 12:29 WIB).

Tempat ibadah agama Buddha adalah vihara. Salah satu vihara yang ada di Indonesia adalah Vihara Padumuttara yang berlokasi di jalan Bhakti nomor 14 daerah Pasar Lama Kota Tangerang. Menurut Irfan selaku Koordinator Sekolah Minggu Siddharta Vihara Padumuttara berdasarkan Poster Ulang Tahun ke 55 pada tahun 2018, Vihara Padumuttara berdiri pada tahun 1963 (wawancara dengan Irfan via Line pada 17 Oktober 2018 pukul 11.32 WIB). Sementara Sutarman selaku Ketua Kebaktian Bodhicitta Vihara Padumuttara mengatakan kebaktian di Vihara Padumuttara diadakan setiap hari karena ada dua aliran agama Buddha yaitu Theravada dan Mahayana. Jadwal kebaktian Vihara Padumuttara untuk umat Buddha Mahayana diselenggarakan pada hari Rabu dan sisanya adalah hari untuk kebaktian umat Buddha Theravada (wawancara dengan Sutarman di Vihara Padumuttara Tangerang 24 Oktober 2018 pukul 20.28 WIB).

Kegiatan kebaktian Buddha Mahayana di Vihara Padumuttara cukup beragam misalnya berdoa atau sembahyang kepada Tuhan. Dalam jurnal yang berjudul Komunikasi Transendental Manusia-Tuhan, komunikasi yang melibatkan manusia dengan Tuhan menurut Deddy Mulyana disebut komunikasi transendental (Suryani, 2015). Jadi sembahyang yang dilakukan oleh umat Buddha Mahayana di Vihara Padumuttara merupakan bentuk kegiatan komunikasi antara manusia dengan Tuhan sehingga membentuk makna yang dipahami bersama.

\section{Metode Penelitian}

Dalam penelitian ini penulis melakukan pendekatan dengan penelitian kualitatif yang bersifat deskriptif dengan metode studi kasus.

Teknik pengumpulan data dalam penelitian ini dilakukan dengan wawancara terhadap subjek penelitian yaitu pakar Buddha Mahayana, umat Buddha Mahayana yang melakukan sembahyang di Vihara Padumuttara dan pengurus kebaktian Vihara Padumuttara. Narasumber pada penelitian ini adalah Yi Ling Qi selaku Biksu 
Buddha Mahayana di Vihara Avalokitesvara. Yuriani selaku dosen dari Sekolah Tinggi Agama Buddha Sriwijaya, Sutarman selaku ketua pengurus kebaktian Buddha Mahayana di Vihara Padumuttara Tangerang dan Irfan selaku pengurus kebaktian Buddha Theravada untuk anak-anak di Vihara Padumuttara Tangerang yang mendapatkan data sejarah Vihara Padumuttara Tangerang. Selain itu juga dilakukan observasi nonpartisipan, studi kepustakaan dan penelusuran data online.

Data dalam penelitian ini dibagi menjadi dua yaitu data primer dan data sekunder.Menurut Rosady Ruslan dalam jurnal yang berjudul Analisis Penggunaan Twitter Sebagai Media Komunikasi Selebritis di Jakarta, data primer merupakan data yang dihimpun secara langsung dari sumbernya dan diolah sendiri oleh peneliti untuk dimanfaatkan. Data primer yang penulis gunakan berupa wawancara dan observasi. Data sekunder merupakan data penelitian yang diperoleh secara tidak langsung melalui media perantara atau digunakan oleh pihak lain yang bukan merupakan pengelolanya guna dimanfaatkan dalam suatu penelitian tertentu. Data sekunder yang penulis gunakan adalah studi kepustakaan dan penelusuan data online (Azeharie dan Kusuma, 2014).

\section{Hasil Temuan dan Diskusi}

Suhu Yi Ling Qi menjelaskan tata cara sembahyang Buddha Mahayana. Diawali dengan melakukan wensin terlebih dahulu. Kemudian melakukan namaskara sebanyak tiga kali dan ditutup lagi dengan wensin. Selain itu terdapat pradaksina. Pradaksina merupakan tata cara yang paling identik dan umum dilakukan oleh umat Buddha Mahayana (wawancara dengan Suhu Yi Ling Qi di Vihara Avalokitesvara Jakarta pada tanggal 26 Oktober 2018 pukul 12.01 WIB). Selain itu juga terdapat nien fo dalam pradaksina.

Gambar 1. Cuplikan Video Wensin

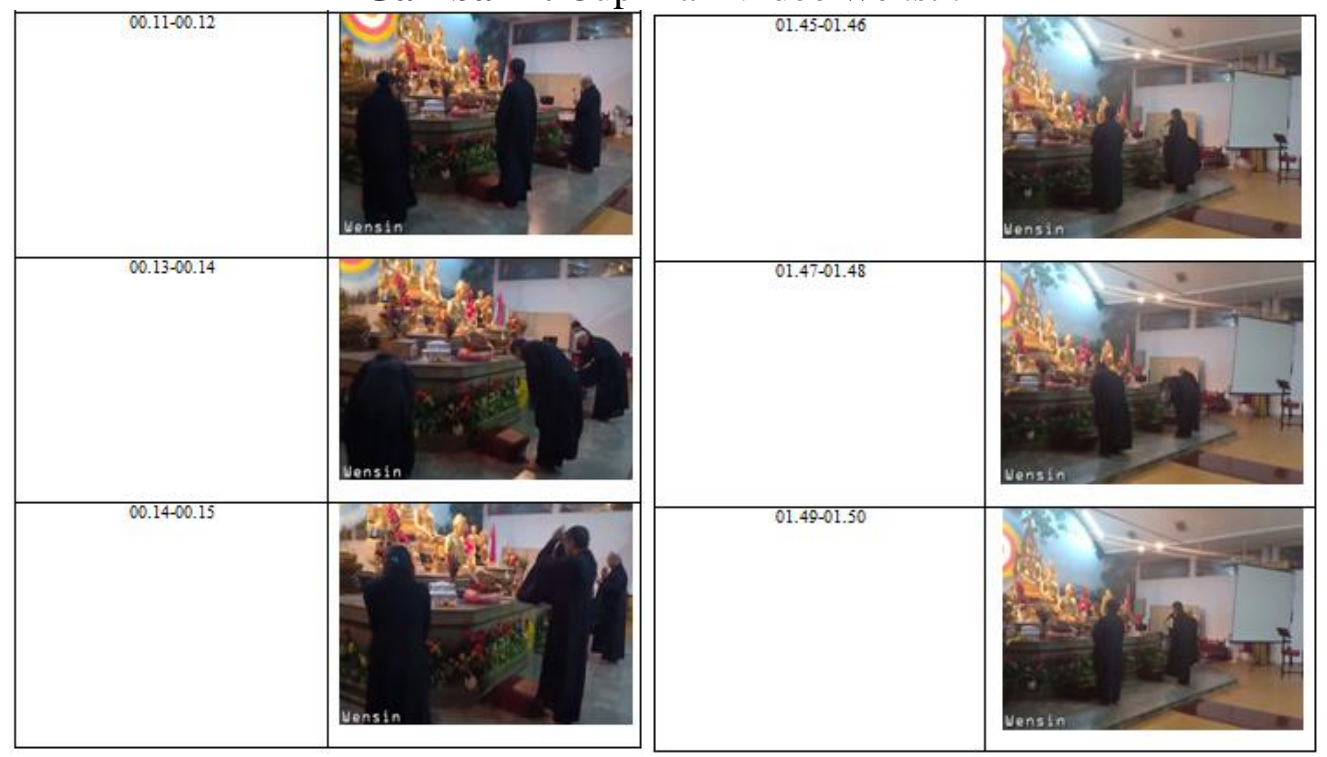

Sumber: Dokumentasi Penulis

Denotasi

Pada waktu 00.11-00.12 dan 01.45-01.46 diawali dengan berdiri tegak, ke dua telapak tangan dirangkupkan yang disebut anjali dan jarak antara kedua telapak kaki sebanding dengan jarak antara kedua bahu (chingtu.net diunduh pada tanggal 1 
November 2018 pukul 20.48 WIB). Pada waktu 00.13-00.14 dan 01.47-01.48 telapak tangan kanan berada di atas telapak tangan kiri dan diletakan di posisi perut. Selanjutnya membungkuk 90 derajat. Kemudian badan tegak dengan kedua tangan membentuk posisi tangan wensin. Posisi tangan wensin membentuk teratai. Cara membentuk teratai yaitu jari kelingking, manis dan tengah pada tangan kanan berada di atas tangan kiri dengan jari yang sama yaitu kelingking, manis dan tengah. Sedangkan ibu jari pada tangan kiri dan tangan kanan bertemu. Sama dengan ibu jari, jari telunjuk pada tangan kanan dan kiri bertemu namun juga membentuk sudut ke atas. Pada waktu 00.14-00.15 posisi tangan wensin yang berbentuk teratai diletakan di atas kening. Terakhir pada waktu 01.49-01.50 tangan dirangkapkan kembali di depan dada (wawancara dengan Yuriani via WhatsApp pada tanggal 1 November 2018 pukul 20.13 WIB).

\section{Konotasi}

Pada waktu 00.11-00.12, 01.45-01.46 dan 01.49-01.50 anjali melambangkan bunga teratai yang masih kuncup (chingtu.net diunduh pada tanggal 1 November 2018 pukul 20.48 WIB). Pada waktu 00.13-00.14 dan 01.47-01.48 saat membungkuk menurut Yuriani dahi patung atau rupang Buddha seolah-olah mencapai tengkuk sehingga hormatnya sangat dalam (wawancara dengan Yuriani di Sekolah Tinggi Agama Buddha Negeri Sriwijaya Tangerang pada tanggal 22 Oktober 2018 pukul 13.33 WIB). Selain itu, membungkuk berarti berendah diri sedangkan posisi tangan wensin melambangkan bunga teratai. Pada waktu 00.11-00.12, 00.13-00.14, 01.4501.46, 01.49-01.50 dan 01.47-01.48 merupakan bentuk menghormat kepada para Buddha sebagai sosok mulia, teragung dan berada di tempat yang tertinggi (wawancara dengan Yuriani via WhatsApp pada tanggal 1 November 2018 pukul 20.13 WIB). Pada waktu 00.14-00.15 melambangkan terbuka kesadaran. Menyadarkan bahwa umat merupakan siswa Buddha. Siswa Buddha tidak bisa tibatiba langsung belajar namun harus memberi hormat terlebih dahulu kepada para Buddha sebagai sosok mulia, teragung dan berada di tempat yang tertinggi (wawancara dengan Suhu Yi Ling Qi di Vihara Avalokitesvara Jakarta pada tanggal 26 Oktober 2018 pukul 12.01 WIB).

\section{Mitos}

Dalam berita yang berjudul 4-12-1959: Pengampunan Untuk Kaisar Terakhir China yang Tragis dikatakan sebelum bertransformasi menjadi Republik Rakyat China, negeri tirai bambu dipimpin oleh Kasiar terakhir bernama Pu Yi. Semua orang di istana harus hormat dengan membungkuk dihadapan Kasiar $\mathrm{Pu} \mathrm{Yi}$ (https://www.liputan6.com/ diunduh pada tanggal 18 Januari 2019 pukul 19.02 WIB).

Dalam artikel National Geogarpic Indonesia yang berjudul Menyikap Simbol Teratai di Klenteng dikatakan bunga teratai masuk ke China melalui pengaruh ajaran Buddha yang menyebar dari India sejak masa Dinasti Qin pada tahun 221-206 SM sehingga teratai menjadi bagian dalam kebudayaan masyarakat China. Bunga teratai merupakan ikon Buddhisme yang diagungkan bermakna kesucian dan kemurinian (http://nationalgeographic.grid.id/ diunduh pada tanggal 18 Januari 2018 pukul 15.01WIB).

Dalam buku yang berjudul Pendidikan Agama Buddha Untuk Sekolah Menengah Atas Kelas 12, setiap orang yang menempuh pendidikan akan memperoleh gelar. Gelar tersebut akan dimiliki dan menjadi bagian dari kehidupan 
seseorang. Begitu juga dalam agama Buddha, orang yang memperoleh gelar Buddha adalah orang yang menempuh ajaran kebenaran atau telah mencapai penerangan sempurna. Buddha merupakan sebuah gelar yang diberikan atau digunakan oleh orang yang telah mencapai kesempurnaan (Mujiyanto, 2009). Kesempurnaan yang dimaksud adalah batin terbebas dari kekotoran nafsu, terbebas dari kelahiran kembali dan kebodohan lenyap digantikan oleh kebijaksanaan (Mujiyanto, 2009).

Gambar 2. Cuplikan Video Namaskara

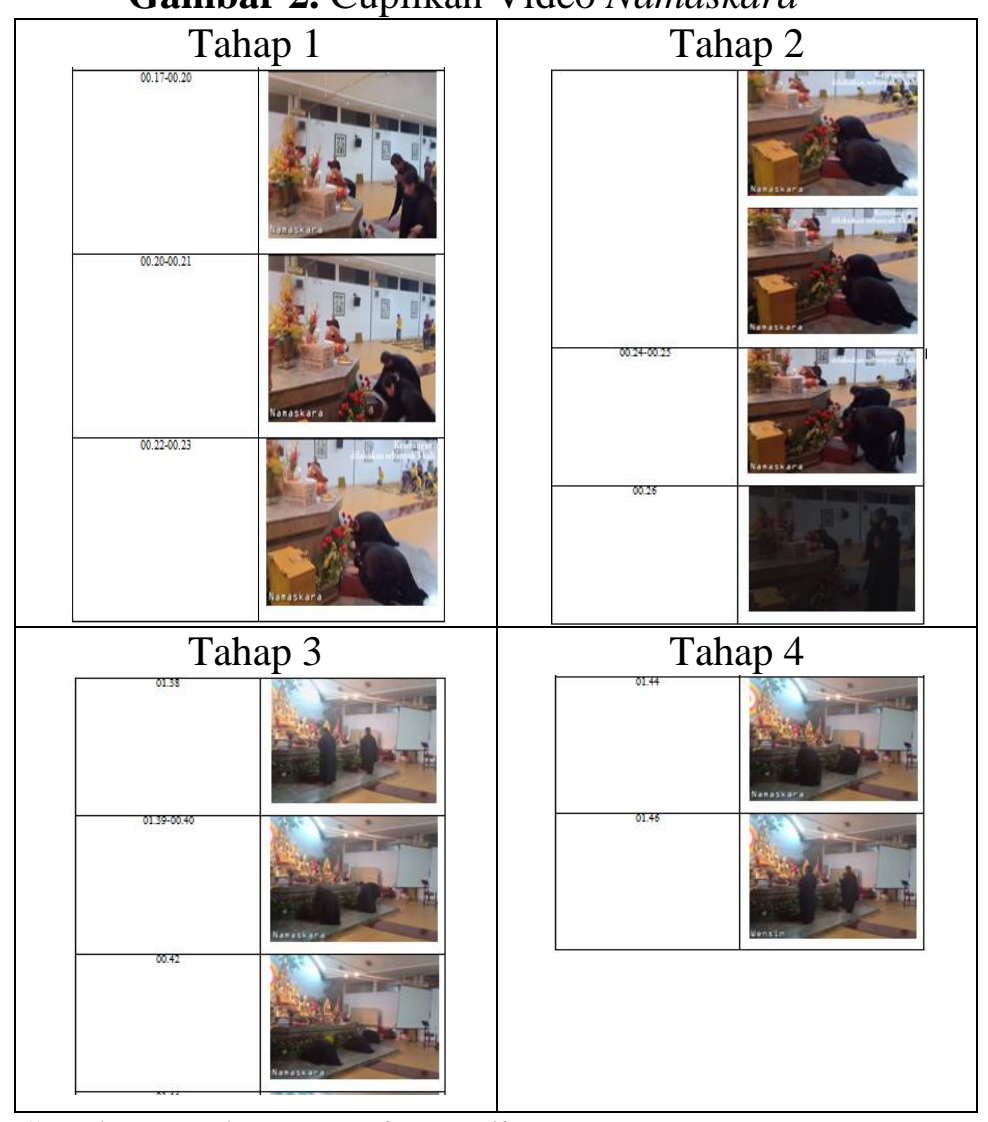

Sumber: Dokumentasi Penulis

Denotasi

Pada waktu 00.17-00.20 dan 01.38 diawali dengan berdiri tegak, ke dua telapak tangan dirangkupkan yang disebut anjali dan jarak antara kedua telapak kaki sebanding dengan jarak antara kedua bahu. Pada waktu 00.20-00.21 dan 01.39-00.40 badan dibungkukan dan dilanjutkan dengan berlutut. Sewaktu hendak berlutut, telapak tangan kanan terlebih dahulu diturunkan ke lantai. Selanjutnya telapak tangan kiri diturunkan ke lantai dengan jarak selebar bahu dan meletakan di depan telapak tangan kanan. Telapak tangan kanan dipindahkan agar sejajar dengan telapak tangan kiri. Pada waktu 00.42 kepala ditundukan hingga menyentuh lantai di antara kedua telapak tangan (chingtu.net diunduh pada tanggal 1 November 2018 pukul 20.48 WIB) serta semua lima titik harus menyentuh lantai. Lima titik itu adalah dahi, telapak tangan, siku, lutut dan kaki. Pada waktu 00.22-00.23 posisi tangan menghadap lantai kemudian dikepalkan sambil diputar selanjutnya tangan dibuka secara perlahan sehingga telapak tangan tidak menghadap lantai (wawancara dengan Suhu Yi Ling Qi di Vihara Avalokitesvara Jakarta pada tanggal 26 Oktober 2018 pukul 12.01 WIB). Paragraf ini menerangkan tahapan berdiri sampai bersujud. 
Lanjutan dari waktu 00.22-00.23 telapak tangan yang tidak menghadap lantai selanjutnya diputar sambil dikepalkan dan tangan dibuka secara perlahan sehingga telapak tangan menghadap ke lantai (wawancara dengan Suhu Yi Ling Qi di Vihara Avalokitesvara Jakarta pada tanggal 26 Oktober 2018 pukul 12.01 WIB). Pada waktu 00.24-00.25 dan 01.44 kepala di angkat. Sedangkan telapak tangan kanan dipindahkan ke belakang telapak tangan kiri dan diletakan antara tengah-tengah kedua lutut. Selanjutnya telapak tangan kiri di angkat. Kemudian telapak tangan kanan mendorong agar badan dan kedua lutut naik. Terakhir yaitu waktu 00.26 dan 01.46 kembali ke posisi awal (chingtu.net diunduh pada tanggal 1 November 2018 pukul 20.48 WIB). Paragraf ini menjelaskan tahapan bersujud sampai berdiri. Menurut Suhu Yi Ling Qi namaskara dilakukan sebanyak tiga kali (wawancara dengan Suhu Yi Ling Qi di Vihara Avalokitesvara Jakarta pada tanggal 26 Oktober 2018 pukul 12.01 WIB).

\section{Konotasi}

Pada waktu 00.17-00.20, 00.26, 01.38 dan 01.46 anjali melambangkan bunga teratai yang masih kuncup. Pada waktu 00.20-00.21, 00.42 dan 01.39-00.40 berarti menyerahkan jiwa dan raga kepada kepada para Buddha sebagai sosok mulia, teragung dan berada di tempat yang tertinggi (chingtu.net diunduh pada tanggal 1 November 2018 pukul 20.48 WIB). Pada waktu 00.17-00.20, 00.26, 01.38 dan 01.46 merupakan bentuk menghormat kepada para Buddha sebagai sosok mulia, teragung dan berada di tempat yang tertinggi (wawancara dengan Yuriani via WhatsApp pada tanggal 1 November 2018 pukul 20.13 WIB). Pada waktu 00.22-00.23 saat tangan dibuka secara perlahan sehingga telapak tangan tidak menghadap lantai berarti umat Buddha Mahayana sedang memohon kepada Buddha untuk dapat mempelajari ajaran atau Dhamma Sang Buddha. Saat tangan dikepalkan perlahan berarti umat Buddha Mahayana menerima ajaran atau Dhamma Sang Buddha dengan sepenuh hati. Selanjutnya tangan menghadap ke lantai berarti umat Buddha Mahayana memberikan kembali ajaran atau Dhamma Sang Buddha kepada semua mahluk. Melakukan Namaskara sebanyak tiga kali melambangkan Buddha, Dhamma dan Sangha (wawancara dengan Suhu Yi Ling Qi di Vihara Avalokitesvara Jakarta pada tanggal 26 Oktober 2018 pukul 12.01 WIB).

Mitos

Dalam jurnal yang berjudul Penerapan Mimesis Dalam Novel Empress Orchid Karya Anchee Min (Penelitian Analisis Isi) dikatakan kowtow adalah bentuk penghormatan tertinggi yang dilakukan terhadap orang tua dan orang yang dihormati dalam budaya China. Kowtow juga dilakukan kepada kaisar pada masa kekaisaran misalnya Kaisar Xuan Yuan. Cara melakukan kowtow adalah dengan berlutut dan bersujud sampai kepala menyentuh tanah (Danyanti, 2018).

Dalam jurnal yang berjudul Perencanaan Vihara Buddha Theravada Dengan Penerapan Karakter Khas Lokal Kaltim di Kota Samarinda dikatakan dalam agama Buddha, Dhamma merupakan ajaran yang disebarkan oleh Sang Buddha. Sangha merupakan orang-orang yang menjadi biksu dan memimpin ibadah (Syarifudin, 2016). 


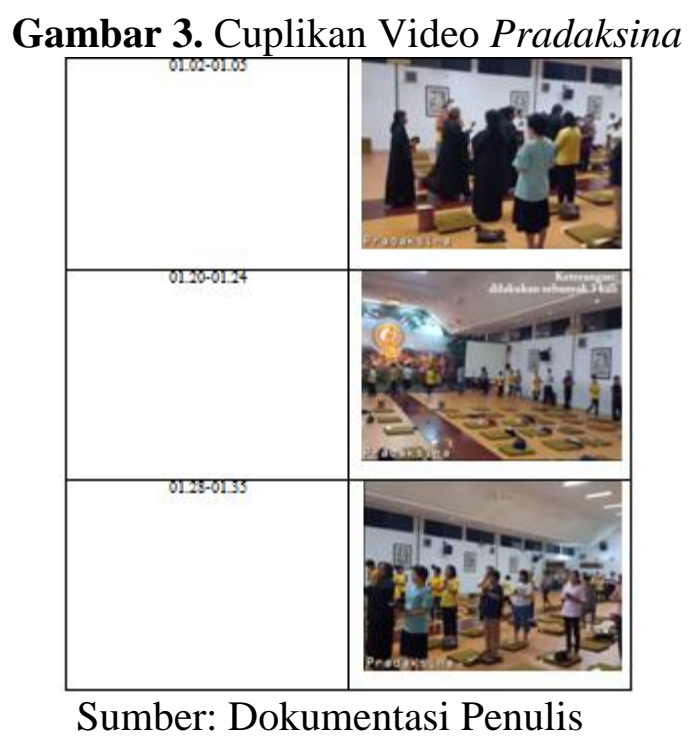

\section{Denotasi}

Pada waktu 01.02-01.05 diawali dengan berdiri dan saling berhadapan. Umat Buddha Mahayana yang berada di sebelah kiri menghadap ke sebelah kanan dan umat Buddha Mahayana yang berada di sebelah kanan menghadap ke sebelah kiri. Posisi tangan bersikap anjali atau dirangkupkan kedepan dada. Pada waktu 01.2001.24 pradaksina dilakukan dengan berjalan memutar searah jarum jam sebanyak tiga kali (wawancara dengan Suhu Yi Ling Qi di Vihara Avalokitesvara Jakarta pada tanggal 26 Oktober 2018 pukul 12.01 WIB). Pada waktu 01.28-01.35 umat Buddha Mahayana kembali ke tempat duduknya.

\section{Konotasi}

Pada waktu 01.02-01.05 posisi saling berhadapan sebenarnya adalah budaya dari China. Budaya dari China ketika raja memasuki ruangan maka semuanya saling berhadapan untuk menghormati raja. Yang dijadikan raja adalah Buddha, Dhamma dan Sangha. Posisi tangan bersikap anjali berarti saling menghormati. Pada waktu 01.20-01.24 berjalan searah jarum jam melambangkan jalan kebenaran (wawancara dengan Suhu Yi Ling Qi di Vihara Avalokitesvara Jakarta pada tanggal 26 Oktober 2018 pukul 12.01 WIB). Pradaksina adalah bentuk penghormatan dan renungan atas sifat-sifat luhur Buddha, Dhamma dan Sangha (wawancara dengan Yuriani via WhatsApp pada tanggal 2 November 2018 pukul 13.20 WIB).

Mitos

\section{Gambar 4. Dinasti Qing}

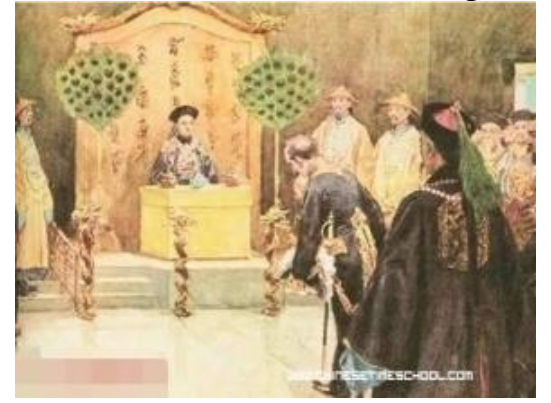

Sumber: www.chinesetimeschool.com diunduh pada 8 Desember 2018 pukul 03.00 WIB 
Gambar di atas menjelaskan bahwa semua orang saling berhadapan kepada satu orang saat Dinasti Qing. Menurut Yuriani mengatakan bahwa Buddha adalah orang yang memperoleh pencerahan. Dhamma adalah ajaran Buddha yang menuntun ke jalan kebahagiaan. Sangha adalah orang yang dapat mensistematisasi ajaran Buddha. Sangha merupakan persamuan biksu yaitu minimal terdiri dari lima biksu (wawancara dengan Yuriani di Sekolah Tinggi Agama Buddha Negeri Sriwijaya pada tanggal 21 Januari 2019 pukul 13.01WIB).

Gambar 5. Cuplikan Video Nien Fo

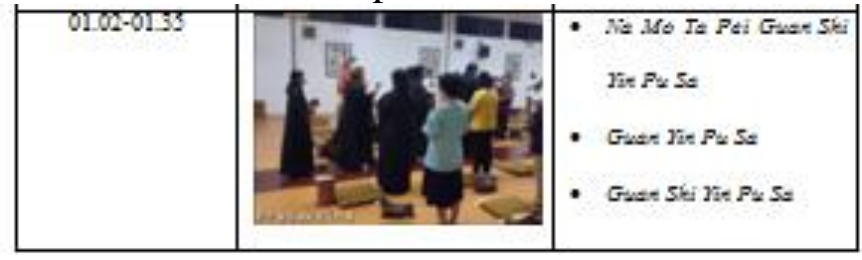

Sumber: Dokumentasi Penulis

\section{Denotasi}

Na Mo Ta Pei Guan Shi Yin Pu Sa, Guan Yin Pu Sa dan Guan Shi Yin Pu Sa.

\section{Konotasi}

Dalam artikel yang berjudul Interpretasi Ta Pei Cou (Mahakaruna Dharani) Oleh Praktisi Theravada, terdapat dua arti dalam $\mathrm{Na} \mathrm{Mo}$. Arti yang pertama yaitu berlindung. Arti yang kedua yaitu mempersembahkan seluruh kehidupan dan tunduk dengan penuh sujud (https://forum.dhammacitta.org/ diunduh pada tanggal 16 Januari 2019 pukul 13.16 WIB). Sedangkan $\mathrm{Ta} P e i$ berarti welas asih dan $P u S a$ berarti Buddha (https://translate.google.co.id/ diunduh pada tanggal 16 Januari 2019 pukul 13.16 WIB).

Selanjutnya dalam artikel yang berjudul Mengenal Lebih Dekat Avalokitesvara, Tingkatan dan Bodhisattva Sila, Avalokite atau Guan atau Guan Shi bermakna melihat ke bawah atau mendengarkan ke bawah. Bawah yang dimaksud bermakna ke dunia yang merupakan suatu alam. Selanjunya Isvara atau Yin berarti suara atau suara jeritan mahluk atas penderitaan yang mereka alami. Guan Yin sebagai seorang calon Buddha yang melambangkan welas asih dan penyayang (https://forum.dhammacitta.org/ diunduh pada tanggal 16 Januari 2019 pukul 13.08 WIB).

\section{Simpulan}

Berdasarkan uraian yang telah dibahas pada bab-bab sebelumnya penulis dapat mengambil kesimpulan bahwa makna Sembahyang Buddha Mahayana dapat dilihat dari makna gerak tubuh dalam sembahyang. Makna gerak wensin adalah bentuk penghormatan kepada Buddha. Makna gerak namaskara adalah bentuk dari penghormatan kepada Buddha dan perenungan terhadap ajaran Sang Buddha. Sedangkan makna gerak pradaksina adalah bentuk penghormatan dan perenungan atas sifat-sifat Buddha, Dhamma dan Sangha. Selain itu juga terdapat nien fo yaitu melafalkan nama Buddha berkali-kali. Sehingga makna semiotika pada sembahyang yang dilakukan oleh umat Buddha Mahayana di Vihara Padumuttara Tangerang adalah sebagai bentuk penghormatan dan perenungan terhadap ajaran atau Dhamma Sang Buddha mencangkup sifat-sifat luhur Buddha. 


\section{Ucapan Terima Kasih}

Ucapan terima kasih diberikan kepada Fakultas Ilmu Komunikasi Tarumanagara dan juga para narasumber yaitu: Yi Ling Qi, Yuriani, Sutarman dan Irfan yang telah membantu sebagai narasumber dan semua pihak yang telah mendukung dan membantu dalam penelitian ini.

\section{Daftar Pustaka}

Aprilia, S., \& Murtiningsi. (2017). Eksistensi Agama Konghucu Di Indonesia. Jurnal Raden Fatah. 1(1). 15-40.

Azeharie, S., \& Octavia Kusuma. (2014). Analisis Penggunaan Twitter Sebagai Media Komunikasi Selebritis di Jakarta. Jurnal Komunikasi, 6(2). 87-88.

Badan Pusat Statistik. (2013). Penduduk Indonesia Hasil Sensus Penduduk 2010. <https://www.bps.go.id/publication/2013/03/05/becb3c0fa2dbec4af7a24430/pen duduk-indonesia-hasil-sp-2010.html>, diunduh pada 17 Oktober 2018 pukul 12:29 WIB.

Cingtu.net. (2013). Tata Cara Atau Sikap Sembahyang Dan Maknanya. $<$ http://chingtu.net/index.php/jadwal-kebaktian/tata-cara-sikap-sembahyangmaknanya/54-tata-cara-sikap-sembahyang>, diunduh pada tanggal 1 November 2018 pukul 20.48 WIB.

Danyati, Ratna. (2018). Penerapan Mimesis Dalam Novel Empress Orchid Karya Anchee Min (Penelitian Analisis Isi). Seminar Nasional Inovasi dan Tren (SNIT) 2018. 1(1). C 1-8.

Marzali, Amri. (2016). Agama dan Kebudayaan. Indonesia Journal of Anthropology. 1(1). 57-75.

Mujiyanto. (2009). Pendidikan Agama Buddha Untuk Sekolah Menengah Atas Kelas 12. Jakarta: CV Yanwreko Wahana Karya.

National Geograohic Indonesia. (2014). Menyikap Simbol Teratai di Kelenteng. $<$ http://nationalgeographic.grid.id/amp/13292393/memecahkan-simbol-bungateratai-negeri-mesir-hingga-nusantara>, diunduh pada tanggal 18 Januari 2018 pukul 15.01WIB.

Suryani, Wahidah. (2015). Komunikasi Transendental Manusia-Tuhan. Jurnal Farabi, 12(1). 150-163.

Suzuki, Beatrice Lane. (2009). Agama Buddha Mahayana. Jakarta: Karaniya.

Syailendra Winu's Blog. (2011). Pengakuan Agama Konghucu di Indonesia. $<$ http://wisnu.blog.uns.ac.id/2011/03/10/pengakuan-agama-khonghucu-diindonesia/>, di unduh pada tanggal 20 Januari 2019 pukul 13.06 WIB.

Syarifudin, Tommy Gunawan. (2016). Perencanaan Vihara Buddha Theravada Dengan Penerapan Karakter Khas Lokal Kaltim di Kota Samarinda. Kurva S Jurnal Mahasiswa, 2(2). 271-283.

Tim Penyusun. (2003). Materi Kuliah Sejarah Perkembangan Agama Budha. Jakarta: CV Dewi Kayana Abadi. 